\title{
Kinetic and Isotherm Studies of Congo Red Adsorption from Aqueous Solution by Biowaste Material
}

\author{
HARPREET KAUR*, SWATI and RAJVIR KAUR \\ Department of Chemistry, Punjabi University, Patiala-147002, Punjab, India \\ hk160777@gmail.com
}

Received 1 August 2014 / Accepted 5 September 2014

\begin{abstract}
Toxicity caused by the presence of synthetic dyes in aquatic system is extremely important from the environmental point of view because most of these dyes are toxic, carcinogenic and mutagenic. In the present work the ability to remove 'Congo red' from aqueous solution has been studied by using waste material Pigeon dropping, as an adsorbent. Effects of various parameters on adsorption process such as; contact time, adsorbent dose, initial dye concentrations, $\mathrm{pH}$ and temperature was studied. The isotherm data was described by the Langmuir and Freundlich adsorption isotherms. The kinetic data were used for modelling from the second-order kinetic models and intra-particle diffusion model. The thermodynamic studies showed that the process is exothermic and physiosorption. The present investigation confirms that Pigeon dropping can be successfully employed as a good adsorbent for the removal of dye from effluent.
\end{abstract}

Keywords: Pigeon dropping, Congo red, Adsorption Isotherms, Kinetics and equilibrium, Thermodynamic.

\section{Introduction}

Dye is an organic compound that has an ability to impart specific color to the substance to which it is being applied. There is a variety of dyes like; acid dyes, basic dyes, azo dyes, mordant dyes, plastic dyes, etc. The main applications ${ }^{1-2}$ of the dyes has been associated with industries like textiles, leather, food, dyeing, cosmetics, etc. The effluents from these industries thus contain dyes as main pollutant ${ }^{3-6}$. Due to their chemical structure, these dyes interfere in the photosynthetic activity of plants since it resists solar radiation penetration, thereby affecting the ecosystem ${ }^{7}$. Secondly these are highly toxic. Consequently, there is a considerable need for the removal of dye from water effluents prior to their discharge in to receiving water ${ }^{8}$. A number of methods such as; physical and chemical methods, which include adsorption ${ }^{9,10}$, electocoagulation ${ }^{11}$, electrochemical ${ }^{12}$ and biodegradation ${ }^{13,14}$ have been used for the removal of dye from the effluents. Among all these methods, adsorption has been found to be very effective for the removal of dyes from effluents ${ }^{15-17}$. Adsorption method provides a direct and economically cheap route for the efficient removal of dyes from effluent. Congo red [1-napthalenesulfonic acid, 3,3'-(4,4'-biphenylene bis (azo)) bis (4amino-) disodium salt] is a benzidine-based anionic diazo dye, this dye is known to 
metabolize to benzidine, a known carcinogen ${ }^{18}$. Congo red mainly occurs in effluents discharged from wood pulp and paper, cotton textile and leather industries and during dyeing operation; about $20 \%$ of it left in the wastewater. It causes skin irritation and allergic dermatitis. The release of the dye from industries causes tremendous chemico-azo stress on aquatic organisms including fishes and some time results in their mass mortality. Thus there is a need to remove the dye from industrial water before discharged in to water bodies. Ancient Mesopotamian, Egyptian, Indian, Talmudic, Greek, and Roman physicians agreed that animal excretion has valuable medical uses. The hugely influential Greek physician Galen reported the use of Pigeon Dropping in wound dressings ${ }^{19}$. Similarly, in India Pigeon dropping has been used in the treatment of Haematemesis ${ }^{20}$. The present work is devoted to the removal of Congo red dye from aqueous solution by adsorption onto Pigeon dropping, thereby studying the adsorption isotherm, kinetics and thermodynamics of the process, which affect the adsorption.

\section{Experimental}

The adsorbent used was pigeon dropping. Pigeon dropping was collected from pigeon store. It was washed with distilled water six times to remove sand, feathers and soluble impurities. The washed dropping was dried in oven and ground to a fine powder and was sieved through micron sized mesh. The dried powder material was preserved in the desiccator for the subsequent use.

\section{Preparation of the stock solution of adsorbate}

The azo dye, Congo red was purchased from S.D. Fine Chemicals, Mumbai, India. All other reagents were of analytical reagent grade. Stock solution (i.e., $125 \mathrm{mg} / \mathrm{L}$ ) of the test reagents were prepared by dissolving Conge red in distilled water. All the other compositions $(25,50$, $75,100 \mathrm{mg} / \mathrm{L}$ ) were prepared by diluting the stock solution with distilled water. The solutions were stored in air tight glass flasks and flask was wrapped with black paper in order to avoid direct contact with sunlight.

\section{Experimental procedure}

Adsorption of Congo red dye was carried out in a batch process by varying the contact time, adsorbent dose, initial dye concentrations, $\mathrm{pH}$ of medium and temperature. A fixed amount of adsorbent $(0.2,0.5,0.8$ and $1.0 \mathrm{~g})$ was mixed with $100 \mathrm{~mL}$ solution of initial dye concentration $(25,50,75$ and $100 \mathrm{mg} / \mathrm{L})$. The mixture was agitated on Remi stirrer at particular temperature. The solution was withdrawn after different intervals of time $(15,30$, 45, 60, 75, 90 and 105 minutes) and was filtered using whatman filter paper. The mixture was allowed to settle and was centrifuged. In all cases, biosorption equilibrium was reached within $60 \mathrm{~min}$. The Congo red concentration in the supernatant was determined with an UVVisible spectrophotometer (Shimadzu- 1800). Absorbance value was recorded at wavelength of maximum of Congo red at $498 \mathrm{~nm}$.

\section{Results and Discussions}

\section{Effect of adsorbent dose}

The effect of adsorbent dosage on the removal of Congo red was carried out by taking $100 \mathrm{~mL}$ dye solution and varying the adsorbent dosage $(0.2,0.5,0.8$ and $1.0 \mathrm{~g})$. The solution was withdrawn at different intervals of time $(15,30,45,60,75,90$ and 105 minutes) then filtered and centrifuged. The amount of dye remain in solution was determined with the help of UVVisible spectrophotometer. The data indicate that percentage removal of dye increases with 
increase of adsorbent dose (Figure 1(a)). As with increase of adsorbent amount, a large surface area and hence adsorption sites are available for adsorption to take place. From Figure 1(b) it may concluded that the adsorption capacity decrease with increase of adsorbent dose. It may be due to reason that at higher adsorbent to dye concentration, there is fast adsorption onto adsorbent surface, which result in low dye concentration in solution, thereby leads to split in flux or concentration gradient between solute concentration in solution and that on surface of adsorbent, i.e., adsorbent surface remains unsaturated and adsorption density decreases ${ }^{21}$.

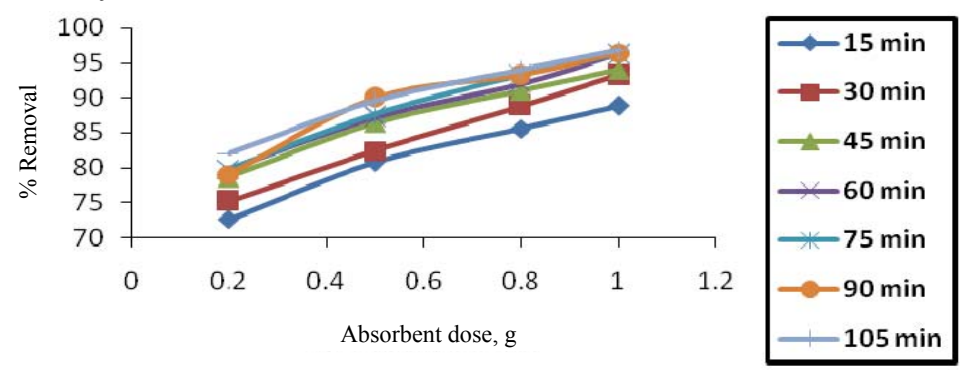

Figure 1(a). Effect of adsorbent dose on the percentage removal of Congo red dye

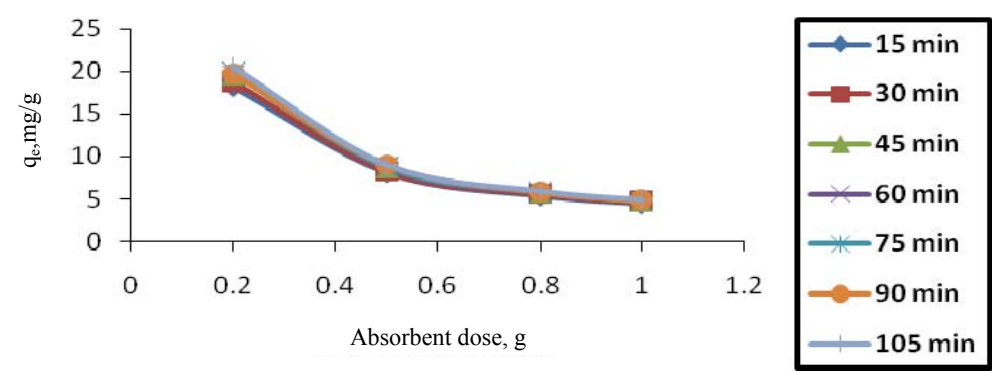

Figure 1(b). Effect of adsorbent dose on the adsorption capacity of dye adsorbed

\section{Effect of contact time}

The study of the effect of contact time on the adsorption of Congo red on Pigeon dropping was carried out by agitating the $100 \mathrm{~mL}$ of solution of dye and $0.8 \mathrm{~g}$ of adsorbent at room temperature with the help of Remi stirrer with constant speed $(430 \mathrm{rpm})$ for the different intervals of time $(15,30,45,60,75,90$ and 105 minutes). Figure 2(a) indicates that the adsorption is rapid at initial stages because initially whole surface of adsorbent is free for adsorption and becomes slow or nearly constant at later stages ${ }^{22}$. This indicates that equilibrium can be assumed to be achieved after 60 minutes. It may be due to saturation of the active site, which does not allow further adsorption to take place. The adsorption capacity of dye with time is given in Figure 2(b) also followed the same pattern. The mechanism assumed that the boundary layer resistance will be affected by the rate of adsorption and increase in contact time, which will reduce the resistance and increase the mobility of dye during adsorption. The equilibrium time required by adsorbent used in this study is less as compared to other adsorbent reported in literature ${ }^{23}$. This is the important tool as considerations for economical wastewater treatments. The instantaneous equilibrium phenomenon is advantages since the shorter contact time effectively allows for a smaller size of contact equipment, which in turn directly affects both the capacity and operational cost of the process. 


\section{Effect of initial dye concentration}

The effect of initial concentration on adsorption capacity of Congo red was determined by carrying out the agitation of different solution of Congo red $(25,50,75,100$ and $125 \mathrm{mg} / \mathrm{L})$ containing fixed amount of adsorbent $(0.8 \mathrm{~g})$ at room temperature and illustrated in Figure 2(a) and Figure 2(b). The data indicate that initially there is rapid adsorption and this is due to an availability of large number of vacant sites at the initial stage ${ }^{3}$. As the time proceeded there is an accumulation of dye particles in the vacant sites leading to decrease in adsorption rate at the later stages.

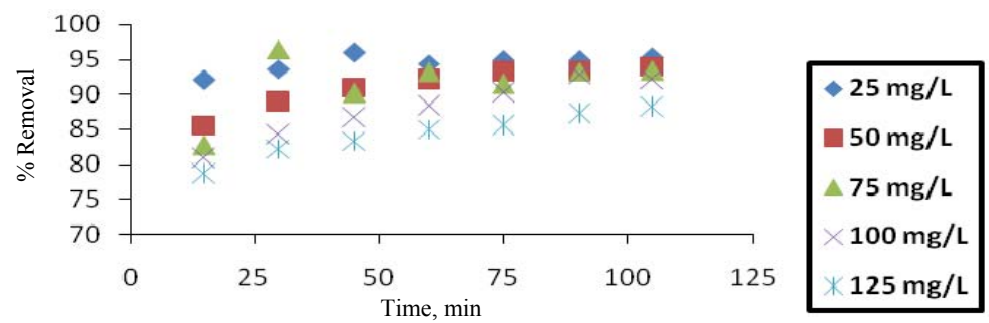

Figure 2(a). Effect of initial dye concentration and time on percent removal of Congo red onto pigeon dropping

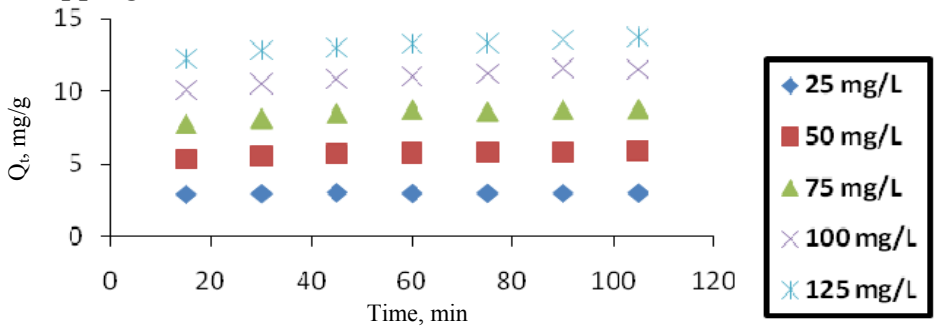

Figure 2(b). Effect of initial dye concentration and time on adsorption capacity of Congo red onto pigeon dropping

\section{Effect of $\mathrm{pH}$}

The $\mathrm{pH}$ of adsorption medium is one of the important parameter on which rate of adsorption depends. The effect of $\mathrm{pH}$ on dye adsorption was determined by varying the $\mathrm{pH}(2.4,6.3$ and 10.4) of solution. Experiment was carried out by agitating the $100 \mathrm{~mL}$ of dye solution $(100 \mathrm{mg} / \mathrm{L})$ containing fixed amount of adsorbent $(0.8 \mathrm{~g})$ at room temperature. Figure 3 shows that percent removal remains constant at low $\mathrm{pH}$, but decreases when $\mathrm{pH}$ changes from 6.3 to 10.4, i.e., when solution become alkaline. The decrease in adsorption of dye with increase of $\mathrm{pH}$ may be attributed to reason that the polarisation of adsorbent decreases in alkaline medium.

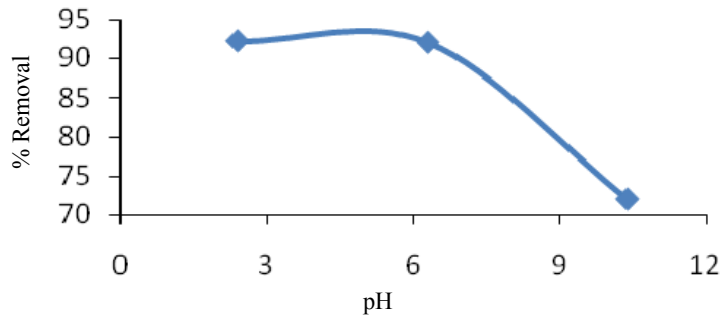

Figure 3. Effect of $\mathrm{pH}$ on the percentage removal of Congo red dye 


\section{Adsorption isotherms}

Adsorption isotherm indicates how the adsorption molecules distribute between the solid phase and liquid phase when the adsorption process reaches an equilibrium state. In this work, Langmuir and Freundlich model were used to describe the relationship between amounts of dye adsorbed $\left(\mathrm{q}_{\mathrm{e}}\right)$ and its equilibrium concentration $\left(\mathrm{C}_{\mathrm{e}}\right)$.

\section{Langmuir adsorption isotherm}

Langmuir adsorption isotherm assumes that adsorption takes place at specific homogenous sites within adsorbent. The Langmuir equation ${ }^{24}$ can be represented as:

$$
\frac{C_{e}}{q_{e}}=\frac{C_{e}}{q_{m}}+\frac{1}{q_{m} \cdot b_{L}}
$$

Where, $\mathrm{q}_{\mathrm{e}}$ is the amount of dye adsorbed $(\mathrm{mg} / \mathrm{g}), \mathrm{C}_{\mathrm{e}}$ is the equilibrium concentration of the adsorbate $(\mathrm{mg} / \mathrm{L}), \mathrm{q}_{\mathrm{m}}$ is a constant related to the area occupied by a monolayer of adsorbate, reflecting the maximum adsorption capacity $(\mathrm{mg} / \mathrm{g})$ and $\mathrm{b}_{\mathrm{L}}$ is Langmuir adsorption equilibrium constant $(\mathrm{L} / \mathrm{mg})$ that is related to the apparent energy of adsorption. The plot of $\mathrm{C}_{\mathrm{e}} / \mathrm{q}_{\mathrm{e}}$ versus $\mathrm{C}_{\mathrm{e}}$ for the adsorption of Congo red by adsorbent are illustrated in Figure 4 and data is listed in Table 1, it shows a linear relationship which confirms the applicability of the Langmuir model for the adsorption process. The value of $\mathrm{q}_{\mathrm{m}}$ and $\mathrm{b}$ were calculated from slope and intercepts of the plots and are listed in Table 1. The feasibilities of the adsorption processes are calculated by the dimensionless separation factor ${ }^{3}\left(R_{L}\right)$, which is defined by:

$$
R_{L}=\frac{1}{\left(1+b_{L} \cdot C_{0}\right)}
$$

The parameter value of $\mathrm{R}_{\mathrm{L}}<1.0$ indicates the favourable adsorption for the adsobateadsorbent system.

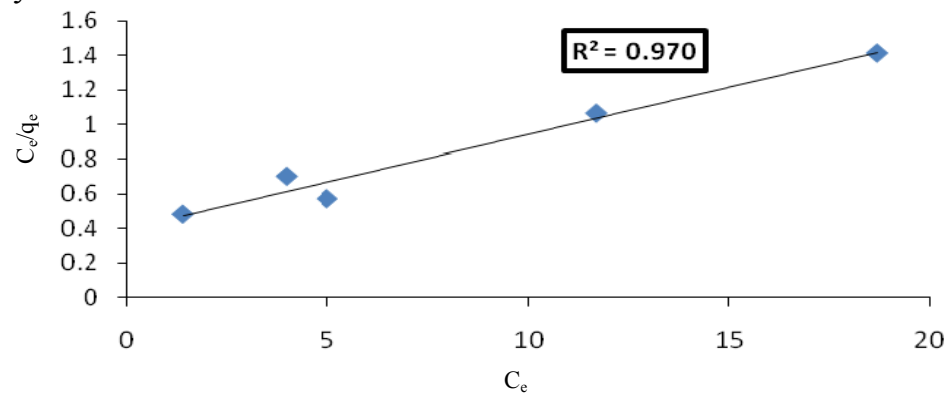

Figure 4. Langmuir Isotherm for the adsorption of Congo red onto pigeon dropping

Table 1. Langmuir and Freundlich Isotherms parameters for Congo red on Pigeon dropping

\begin{tabular}{ccccccc}
\hline Temperature & \multicolumn{3}{c}{ Langmuir Isotherm } & \multicolumn{3}{c}{ Freundlich Isotherm } \\
\cline { 2 - 7 } $\mathrm{K}$ & \multicolumn{2}{c}{ Statistical parameters/constants } & \multicolumn{2}{c}{ Statistical parameters/constants } \\
& $\mathrm{R}^{2}$ & $\mathrm{q}_{\mathrm{m}}(\mathrm{mg} / \mathrm{g})$ & $\mathrm{b}_{\mathrm{L}}(\mathrm{L} / \mathrm{mg})$ & $\mathrm{R}^{2}$ & $\mathrm{~K}_{\mathrm{f}}$ & $\mathrm{n}$ \\
\hline 305 & 0.9700 & 18.45 & 0.13 & 0.9420 & 2.6903 & 1.73 \\
\hline
\end{tabular}

\section{Freundlich adsorption isotherm}

The Freundlich adsorption isotherm is an empirical equation ${ }^{25}$ used to describe heterogeneous systems is: 


$$
\log q_{e}=\log K_{f}+\frac{1}{n} \log C_{e}
$$

Where, $\mathrm{q}_{\mathrm{e}}$ is the amount adsorbed at equilibrium $(\mathrm{mg} / \mathrm{g}), \mathrm{K}_{\mathrm{f}}$ is the Freundlich constant, $1 / \mathrm{n}$ is the heterogeneity factor which is related to the capacity and intensity of the adsorption and $\mathrm{C}_{\mathrm{e}}$ is the equilibrium concentration $(\mathrm{mg} / \mathrm{L})$.

The plots of $\log \mathrm{q}_{\mathrm{e}}$ versus $\log \mathrm{C}_{\mathrm{e}}$ at temperature $305 \mathrm{~K}$ are illustrated in Figure 5. It shows a linear relationship, which shows the applicability of Freundlich isotherm. The Freundlich constants $\mathrm{K}_{\mathrm{f}}$ and $\mathrm{n}$ are calculated from plots and their values are listed in Table 1 . From the value of $\mathrm{n}$, the nature of adsorption and favourability can be identified. From data listed in Table 1, the magnitude of the $\mathrm{n}$ values, i.e., $\mathrm{n}>1$, which indicates the favourable adsorption of Congo red by adsorbent ${ }^{8}$.

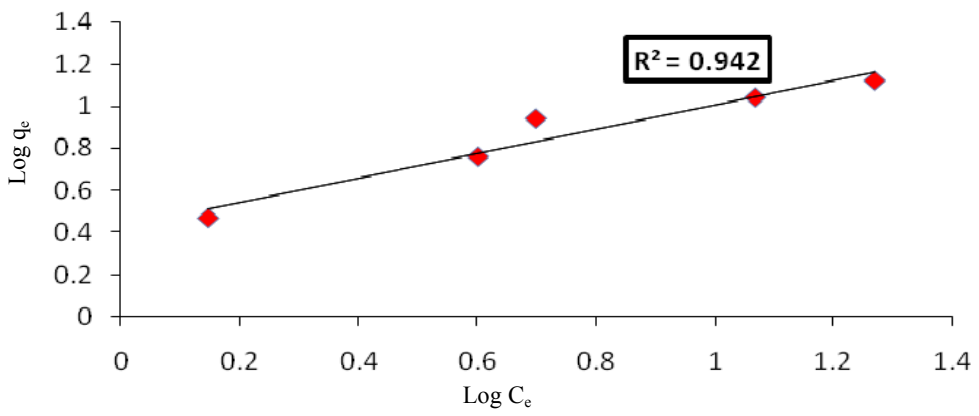

Figure 5: Freundlich adsorption Isotherm for Congo red onto pigeon dropping

\section{Kinetic studies}

Kinetic models are used to examine the rate of adsorption process. Three simplified kinetic models were adopted to examine the mechanism of the adsorption process, which are discussed as:

\section{Pseudo-first order kinetic model}

Pseudo-first order kinetic model describe the adsorption rate based on adsorption capacity. Pseudo-first order equation ${ }^{23}$ describes the kinetics of adsorption process as follows:

$$
\log \left(q_{e}-q_{t}\right)=\log q_{e}-\frac{K_{1}}{2.303} t
$$

Where, $\mathrm{q}_{\mathrm{e}}$ is the amount of dye adsorbed at equilibrium $(\mathrm{mg} / \mathrm{g}), \mathrm{q}_{\mathrm{t}}$ is the amount of dye adsorbed at any time $\mathrm{t}(\mathrm{mg} / \mathrm{g})$, and $\mathrm{K}_{1}$ is the first order rate constant $\left(\mathrm{min}^{-1}\right)$. But the data confirm the non applicability of the pseudo-first order model for the adsorption process.

\section{Pseudo-second order kinetic model}

Pseudo-second order model assumes that adsorption process follow second order mechanism. The rate of pseudo-second order reaction ${ }^{26}$ is expressed by the equation:

$$
\frac{t}{q_{t}}=\frac{1}{K_{2} \cdot q_{e}^{2}}+\frac{1}{q_{e}} t
$$

Where, $\mathrm{K}_{2}$ is the pseudo-second order rate constant $(\mathrm{g} / \mathrm{mg} / \mathrm{min}), \mathrm{q}_{\mathrm{e}}$ is the amount of dye adsorbed on the adsorbent at equilibrium $(\mathrm{mg} / \mathrm{g})$ and $\mathrm{q}_{\mathrm{t}}$ is the amount of dye adsorbed on the adsorbent at any time $\mathrm{t}(\mathrm{mg} / \mathrm{g})$. 
The plots of $\mathrm{t} / \mathrm{q}_{\mathrm{t}}$ versus $\mathrm{t}$ for different initial concentration of Congo red are illustrated in Figure 6 and data is listed in Table 2. The linear plot shows that the correlation coefficients are closer to unity. This suggests that adsorption system can be better represented by the pseudo-second order model.

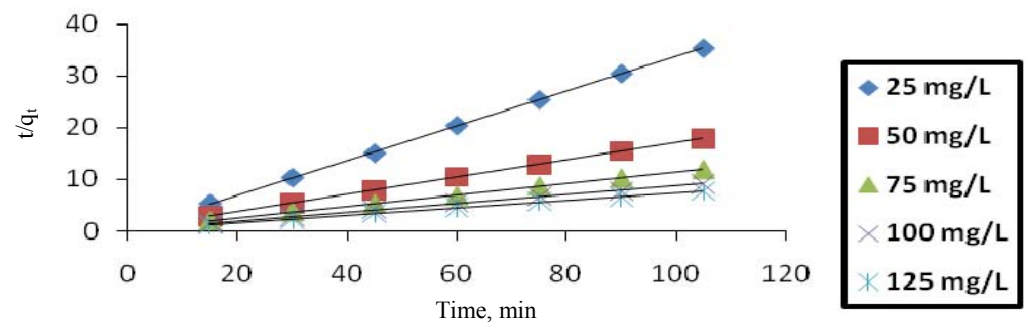

Figure 6. Pseudo-second order kinetics for adsorption of Congo red by pigeon dropping at various initial dye concentrations

Table 2. Pseudo-second-order and Intra-particle diffusion parameters for the adsorption of Congo red dye on pigeon dropping

\begin{tabular}{ccccccc}
\hline & \multicolumn{2}{c}{ Pseudo-second-order parameters } & \multicolumn{3}{c}{ Intra-particle diffusion parameters } \\
\cline { 2 - 7 } $\mathrm{mg} / \mathrm{L}$ & $\begin{array}{c}\mathrm{K}_{2} \\
\mathrm{~g} / \mathrm{mg} / \mathrm{min}\end{array}$ & $\begin{array}{c}\mathrm{q}_{\mathrm{e}} \\
\mathrm{mg} / \mathrm{g}\end{array}$ & $\mathrm{R}^{2}$ & $\begin{array}{c}\mathrm{K}_{\text {ipd }} \\
\mathrm{mg} / \mathrm{g} / \mathrm{min}\end{array}$ & $\begin{array}{c}\mathrm{C} \\
\mathrm{mg} / \mathrm{g}\end{array}$ & $\mathrm{R}^{2}$ \\
\hline 25 & 0.7808 & 2.9833 & 0.9999 & 0.0127 & 2.8552 & 0.5130 \\
50 & 0.0785 & 5.9772 & 0.9999 & 0.0802 & 5.0965 & 0.9456 \\
75 & 0.0418 & 9.0009 & 0.9997 & 0.1577 & 7.2899 & 0.8739 \\
100 & 0.0221 & 11.9190 & 0.9992 & 0.2365 & 9.2183 & 0.9748 \\
125 & 0.0246 & 14.0252 & 0.9996 & 0.2195 & 11.529 & 0.9766 \\
\hline
\end{tabular}

Intra-particle diffusion model

In batch adsorption process, initially adsorption takes place at the surface of adsorbent. In addition, there is possibility of the adsorbate to diffuse within the pores of adsorbent. Intra particle diffusion model was studied to identifying the diffusion mechanism. The Intraparticle diffusion ${ }^{27}$ can be defined as:

$$
q_{t}=K_{i p d} \cdot t^{1 / 2}+C
$$

Where, $\mathrm{q}_{\mathrm{t}}$ is the amount of dye adsorbed at time $\mathrm{t}(\mathrm{mg} / \mathrm{g}), \mathrm{C}$ is the constant $(\mathrm{mg} / \mathrm{g})$, which gives the thickness of the boundary layer and $\mathrm{K}_{\mathrm{ipd}}$ is the intra-particle diffusion rate constant ( $\mathrm{mg} / \mathrm{g}$ min).

The plots between $\mathrm{q}_{\mathrm{t}}$ versus $\mathrm{t}^{1 / 2}$ for various concentration of Congo red are illustrated in Figure 7. The Intra-particle diffusion rate constant $\left(\mathrm{K}_{\mathrm{ipd}}\right)$ and $\mathrm{C}(\mathrm{mg} / \mathrm{g})$ are calculated from the slope and intercept of the plot and along with their regression coefficient are listed in Table 2. According to this model, a linear plot of $\mathrm{q}_{\mathrm{t}}$ versus $\mathrm{t}^{1 / 2}$ indicated that the uptake process was controlled by intra-particle diffusion. The value of constant $\mathrm{C}$ was increases with increase in initial concentration of dye, which indicates the decrease of the chance of the external mass transfer and hence increase of the chance of internal mass transfer due to increase in the thickness of boundary layer.

\section{Thermodynamics studies}

Adsorption process was carried out at three different temperatures ( $305 \mathrm{~K}, 313 \mathrm{~K}$ and $323 \mathrm{~K}$ ) in order to calculate the thermodynamic parameter such as enthalpy change, entropy change 
and Gibb's free energy change. The data listed in Table 3, indicate that the negative value of $\Delta G$ i.e., feasibility of adsorption ${ }^{27}$. Negative value of $\Delta H$ at different temperature for the process further confirms the exothermic nature of process. The low value of $\Delta \mathrm{H}$ confirms that adsorption of Congo red on pigeon dropping is physical adsorption.

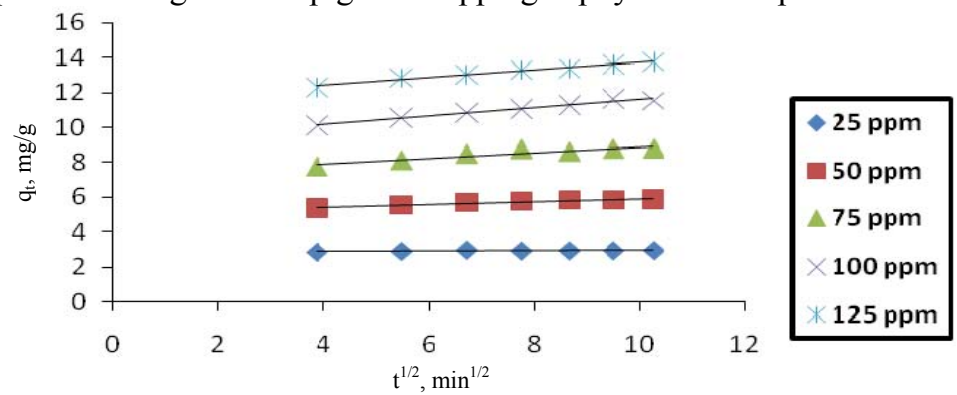

Figure 7. Intra particle diffusion for the removal of Congo red over pigeon dropping

Table 3. Equilibrium constant and thermodynamic parameters for the adsorption of Congo red onto pigeon dropping

\begin{tabular}{ccccccccc}
\hline $\mathrm{C}_{\mathrm{o}}$, & $-\Delta \mathrm{H}$ & $\Delta \mathrm{S}$ & \multicolumn{3}{c}{$\mathrm{K}_{\mathrm{o}}$} & \multicolumn{3}{c}{$-\Delta \mathrm{G}, \mathrm{kJ} / \mathrm{mol}$} \\
\cline { 5 - 9 } $\mathrm{mg} / \mathrm{L}$ & $\mathrm{kJ} / \mathrm{mol}$ & $\mathrm{kJ} / \mathrm{mol} / \mathrm{K}$ & $305 \mathrm{~K}$ & $313 \mathrm{~K}$ & $323 \mathrm{~K}$ & $305 \mathrm{~K}$ & $313 \mathrm{~K}$ & $323 \mathrm{~K}$ \\
\hline 25 & 3.340 & 0.012 & 16.86 & 14.63 & 15.66 & 7.163 & 6.982 & 7.390 \\
50 & 21.328 & -0.044 & 11.50 & 16.86 & 7.19 & 6.193 & 7.352 & 5.301 \\
75 & 35.435 & -0.092 & 14 & 12.39 & 6.43 & 6.692 & 6.551 & 4.997 \\
100 & 8.241 & -0.003 & 7.55 & 15.67 & 6.30 & 5.126 & 7.161 & 4.943 \\
125 & 0.322 & 0.019 & 5.68 & 11.02 & 5.72 & 4.405 & 6.246 & 4.648 \\
\hline
\end{tabular}

Scanning electron microscopy (SEM) analysis

Scanning Electron Microscope is a type of electron microscope capable of creating magnified images of sample surface, which have high resolution. In SEM analysis, the production of magnified images is due to electrons instead of light waves which also provides SEM images with characteristic three dimensional appearance and useful for judging the surface structure of the sample. The SEM image of pigeon dropping before adsorption in Figure 8(a) shows the presence of significant number of pores providing a suitable position for dyes to be adsorbed. SEM images after Congo red adsorption in Figure 8(b) demonstrated that the pores and cavities of adsorbent were efficiently packed with dye.

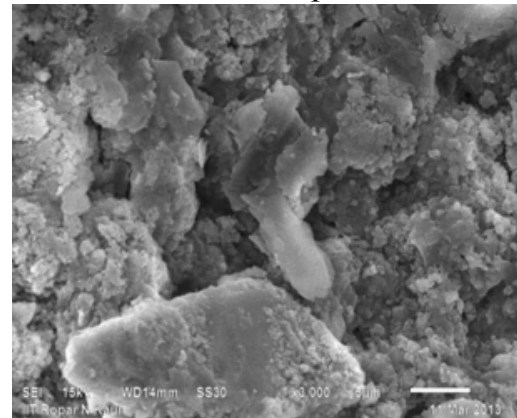

Figure 8(a). SEM image of Pigeon the dropping before the adsorption

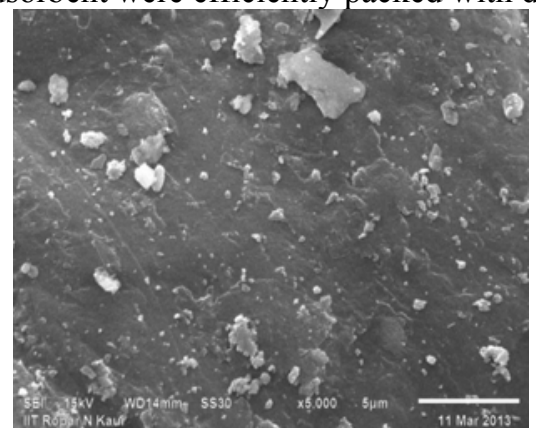

Figure 8(b). SEM image of the Pigeon dropping after the adsorption 


\section{Conclusion}

The results of the present investigation show that biowaste material-Pigeon dropping without giving any pre-treatment has considerable potential for the removal of hazardous Congo red dye from aqueous solution. The equilibrium data have been analyzed using Langmuir and Freundlich isotherms. The characteristic parameters for each isotherm and related correlation coefficients showed that the Pigeon dropping can be effectively used for the removal of Congo red from aqueous solution. The adsorption process follows the pseudo-second order kinetic model $\left(\mathrm{R}^{2}=0.999\right)$. The negative value of $\Delta \mathrm{G}$ implies that the process is spontaneous in nature. The low values of $\Delta \mathrm{H}$ indicate that the forces between adsorbate and adsorbent are weak, i.e., in case of physiosorption. Thus the work established that Pigeon dropping has excellent low-cost bioadsobent for the removal of Congo red, which also affects both the adsorption capacity and operation cost of the process.

\section{References}

1. Yousefi N, Fatehizadeh A, Azizi E, Ahmadian M, Ahmadi A, Zadeh A R and Toolabi A, Sacha J Environ Studies, 2011, 1(2), 81-91.

2. Ip A W M, Barford J P and Mckay G, J Colloid Interface Sci., 2009, 337(1), 32-38; DOI:10.1016/j.jcis.2009.05.015

3. Vijayakumar G, Tamilarasan R and Dharmendirakumar M, J Mater Environ Sci., 2012, 3(1), 157-170.

4. Ho Y S and Mckay G, Can J Chem Eng., 1998, 76(4), 822-827; DOI:10.1002/cjce.5450760419

5. Walker G M, Hansen L, Hanna J A and Allen S J, Water Res., 2003, 37(9), 20812089; DOI:10.1016/S0043-1354(02)00540-7

6. Stydini M, Dimitris I K and Verykios X E, Appl Catal B: Environ.. 2004, 47(3), 189201; DOI:10.1016/j.apcatb.2003.09.014

7. Syed Shabudeen P S, Res J Chem Sci., 2011, 1(1), 88-104.

8. Dogan M, Alkan M and Onganer Y, Water Air Soil Pollut., 2000, 120(3-4), 229-248; DOI:10.1023/A:1005297724304

9. Khan T A, Singh V V and Kumar D, J Sci Ind Res., 2004, 63, 355.

10. Khosravi $M$ and Azizian S, J Ind Eng Chem., 2014, 20(4), 2561-2567; DOI:10.1016/j.jiec.2013.10.040

11. Kobya M, Can O T and Bayramoglu M, J Hazard Mater., 2003, 100(1-3), 163-178; DOI:10.1016/S0304-3894(03)00102-X

12. El-Ashtoukhy E S Z, Int J Electrochem Sci., 2013, 8, 846-858.

13. Naimabadi A, Movahedian Attar H and Shahsavani A, Iran J Environ Health Sci Eng., 2009, 6(2), 67-72.

14. Isik M and Sponza D T, Process Biochem.. 2003, 38(8), 1183-1192; DOI:10.1016/S0032-9592(02)00282-0

15. Etim U J, Inam E, Umoren S A and Eduok U M, Int J Environ Bioenerg., 2013, 5(2), 62-79.

16. Uddin M T, Rukanuzzaman M, Khan M M R and Islam M A, J Environ Manage., 2009, 90(11), 3443-3450; DOI:10.1016/j.jenvman.2009.05.030

17. Gong R, Zhang X, Liu H, Sun Y and Liu B, Bioresour Tech., 2007, 98(6), 13191323; DOI:10.1016/j.biortech.2006.04.034

18. Han R, Ding D, Xu Y, Zou W, Wang Y, Li Y and Zou L, Bioresour Tech..,2008, 99(8), 2938-2946; DOI:10.1016/j.biortech.2007.06.027

19. Staden V, De Compositione Medicamentorum Per Gener, 1989, 3.6, 18. 
20. Charak Samhita Part II, Chikitsa Sathan Chapter-4, Raktpitt-Chikitsa Adhay, Chaukambha Bharati Academy, 2006, 72, 189.

21. Reddy S S, Kotaiah B, Reddy N S P, Bull Chem Soc Ethiop., 2008, 22(3), 369-378.

22. Maghri I, Kenz A, Elkouali M, Tanane O, Talbi M, J Mater Environ Sci., 2012, 3(1), 121-136.

23. Mittal A, Kurup L and Mittal J, J Hazard Mater., 2007, 146(1-2), 243-248; DOI:10.1016/j.jhazmat.2006.12.012

24. Langmuir I, J Am Chem Soc., 1918, 40(9), 1361-1403; DOI:10.1021/ja02242a004

25. Freundlich H, J Phys Chem., 1906, 57A, 385-470.

26. Ho Y S and Mckay G, Process Biochem. 1999, 34, 451.

27. Weber W J and Morris J C, J Sanit Eng Div Am Soc Civ Eng., 1963, 89, 31-59. 